\title{
Abordagens de sexualidade e gênero na saúde do homem: uma revisão integrativa
}

\author{
Sexuality and gender approaches in man's health: an integrative review \\ Enfoques de la sexualidad y el género en la salud de los hombres: una revisión \\ integradora
}

lasmin Belém Silva Queiroz ${ }^{1}$, Allex Alves Sobral de Sousa ${ }^{1 *}$, Cícera Alves de Luna ${ }^{1}$, Lucineide Coqueiro Gurgel ${ }^{1}$, Samyra Maria Lima Sampaio ${ }^{1}$, Thayná Bezerra de Luna ${ }^{1}$, Carmelita Maria Silva Sousa ${ }^{1}$, Abigail de Almeida Cordeiro¹, Dayse Christina Rodrigues Pereira Luz², Willma José de Santana².

\section{RESUMO}

Objetivo: O estudo teve como objetivo identificar na literatura as abordagens de saúde sobre sexualidade e gênero na saúde do homem. Métodos: Para tanto, optou-se por realizar uma revisão integrativa utilizandose as bases de dados LILACS, PUBMED e SCIELO, estudos em língua portuguesa, inglesa e espanhola, disponíveis na íntegra e publicados no período de 2015 a 2019. A amostra do estudo foi composta de 11 artigos, construindo duas categorias temáticas: Abordagens de gênero na saúde do homem e Abordagens de sexualidade, saúde sexual, reprodutiva e paternidade na saúde masculina. Resultados: Os artigos evidenciaram um compêndio de conhecimentos importantes sobre a saúde do homem, identificando que as abordagens de gênero e sexualidade masculina são influenciadas pelo contexto sociocultural de estereótipo de identidade masculina com a necessidade da ressignificação do ser homem no contexto de saúde no Brasil. Considerações Finais: Portanto, recomenda-se a atenção a essas ações no âmbito da atenção básica de saúde, almejando-se atuações com foco nas singularidades e vulnerabilidades masculinas, os cuidados para a promoção de saúde dessa população e estímulo ao envolvimento enquanto sujeito produtor de saúde da família, proporcionando maior participação e empoderamento do homem na saúde.

Palavras-chave: Saúde do homem, Masculinidade, Identidade de gênero.

\begin{abstract}
Objective: The study aimed to identify in the literature the health approaches to sexuality and gender in men's health. Methods: To this end, we chose to conduct an Integrative Review using the LILACS, PUBMED and SCIELO databases, studies in Portuguese, English and Spanish, available in full and published in the period from 2015 to 2019. The sample of The study was composed of 11 articles, constructing two thematic categories: Gender approaches to men's health and Approaches to sexuality, sexual, reproductive health and paternity in male health. Results: The articles evidenced a compendium of important knowledge about men's health, identifying that the approaches of gender and male sexuality are influenced by the sociocultural context of the stereotype of male identity with the need for the resignification of men in the health context in Brazil. Final Considerations: Therefore, attention to these actions in the context of primary health care is recommended, aiming at actions focusing on male singularities and vulnerabilities, care for the health promotion of this population and stimulating involvement as a family health producer, providing greater participation and empowerment of men in health.
\end{abstract}

Key words: Men's health, Masculinity, Gender identity.

\section{RESUMEN}

Objetivo: El estudio tuvo como objetivo identificar los enfoques de salud de la sexualidad y el género en la salud de los hombres en la literatura. Métodos: Para este fin, elegimos realizar una Revisión Integrativa utilizando las bases de datos LILACS, PUBMED y SCIELO, estudios en portugués, inglés y español, disponibles en su totalidad y publicados en el período de 2015 a 2019. La muestra de El estudio estuvo compuesto por 11 artículos, construyendo dos categorías temáticas: enfoques de género para la salud de los

${ }^{1}$ Atenas College University, Orlando - Flórida (EUA). *E-mail: allexsobralfisio@hotmail.com

2 Faculdade do Juazeiro do Norte (FJN), Juazeiro do Norte - CE.

SUBMETIDO EM: 1/2020

ACEITO EM: 2/2020

PUBLICADO EM: $3 / 2020$

REAS/EJCH | Vol.Sup.n.43 | e3000 | DOI: https://doi.org/10.25248/reas.e3000.2020 Página 1 de 10 
hombres y sexualidad, enfoques sexuales, reproductivos y de paternidad para la salud masculina. Resultados: Los artículos mostraron un compendio de conocimientos importantes sobre la salud de los hombres, identificando que los enfoques de género y sexualidad masculina están influenciados por el contexto sociocultural del estereotipo de identidad masculina con la necesidad de volver a significar ser un hombre en el contexto de la salud en Brasil. Consideraciones finales: Por lo tanto, se recomienda prestar atención a estas acciones dentro del alcance de la atención primaria de salud, con el objetivo de acciones enfocadas en las singularidades y vulnerabilidades masculinas, cuidar la promoción de la salud de esta población y alentar la participación como un tema que produce salud familiar, proporcionando mayor participación y empoderamiento de los hombres en salud.

Palabras clave: Salud del hombre, Masculinidad, Identidad de género.

\section{INTRODUÇÃO}

Por muito tempo o homem não foi um ser protagonista na esfera da saúde pública. Sendo a mulher, criança e idosos as prioridades de programas e políticas públicas no Brasil. Diversos fatores influenciaram no afastamento masculino das ações de prevenção e promoção da saúde, são eles: fatores culturais, sociais, pessoais e estruturais (CARNEIRO LMR, et al., 2016). Cenário reforçado por influência da masculinidade, aspectos relacionados ao gênero e a sexualidade que contribuíram para uma construção sociocultural de um ser forte e viril ausente nas unidades de atenção básica, despreocupado com cuidados de saúde e que desprezam o autocuidado pessoal (CARRARA S, et al., 2009). Mas tendo em vista as singularidades e individualidades que perpassa a saúde masculina em 2009 foi publicado a Política Nacional de Atenção Integral à Saúde do Homem (PNAISH), cujo objetivo é promover a saúde integral e holística do homem nos diversos contextos, de forma a assegurar o direito de saúde desses, reduzindo a morbidade e mortalidade por meio do acesso a serviços e ações de saúde efetivo e de qualidade (MINISTÉRIO DA SAÚDE, 2009).

A implementação da PNAISH em muito desconsiderou a construção histórica que envolve o ser homem no contexto de saúde do país, sendo impulsionada principalmente pelas preocupações com neoplasia de próstata (CONNEL RW e MESSERSCHMIDT JW, 2013). A discussão sobre as problemáticas que envolvem as masculinidades, sexualidade e gênero associados ao contexto social e político do país proporcionam instrumentos para a efetivação da PNAISH. Uma vez que o homem deve ser considerado integralmente no bojo de suas vulnerabilidades, para além a atenção pautada nos agravos de saúde (BATISTA KSA e LIMA $A F, 2017)$. Nesse contexto investigativo, o presente artigo discute algumas abordagens de saúde no âmbito de sexualidade e gênero do público masculino, tendo em vista que os aspectos da masculinidade permeiam as proposições da PNAISH, faz-se relevante essa discussão frente à construção de uma assistência integral e holística, voltada a promoção e prevenção de agravos para os homens adultos brasileiros.

Frente ao exposto o estudo tem por objetivo descrever as abordagens de saúde sobre sexualidade e gênero na saúde do homem evidenciada na literatura. $O$ gênero e a sexualidade são elementos que perpassam a saúde do homem, influenciando como este indivíduo ver a sua própria saúde, contribuindo para a construção de comportamentos e atitudes masculinas pouco saudáveis; interferindo assim nos fatores de risco à saúde. A masculinidade atravessa campos que precisam ser trabalhados e ressignificados pelos profissionais, pois é determinante de problematização no âmbito da promoção da saúde (MEYER, et al., 2014).

\section{MÉTODOS}

Trata-se de um estudo bibliográfico do tipo Revisão Integrativa. Esse tipo de pesquisa busca de forma organizada e sistemática promover uma abrangente análise dos estudos disponíveis na literatura, contribuindo para o conhecimento científico, solucionando dúvidas, além de produzir uma síntese de pesquisas já publicados no meio acadêmico. Nesse contexto, entendendo a finalidade do método de Revisão Integrativa, a pesquisa foi estruturada nos seguintes passos: 1) Identificação do tema e seleção da hipótese; 2) Busca na literatura; 3) Categorização dos estudos; 4) Análise de dados; 5) Interpretação dos resultados e 6) Síntese do conteúdo (MENDES KDS, et al., 2008). 
Definiu-se o assunto da pesquisa, e para questão norteadora, estabeleceu a seguinte indagação: De que forma se entende as abordagens de saúde sobre gênero e sexualidade na saúde do homem? Optou-se por realizar um levantamento bibliográfico tendo como fonte de pesquisa as bases de dados: Literatura LatinoAmericana e do Caribe em Ciências da Saúde (LILACS), US National Library of Medicine National Institutes of Health (PUBMED) e Scientific Eletronic Library Online (SCIELO). Logo, conforme validação das palavraschave no portal dos Descritores em Ciência da Saúde (DeCS), para o levantamento das produções científicas foram utilizados como descritores, "Saúde do Homem", "Masculinidade" e "Identidade de Gênero", nos idiomas português, inglês e espanhol, integrados pelo conector booleano and, no campo assunto.

De modo sequencial, foram utilizados como critérios de inclusão dos estudos para esta revisão integrativa: trabalhos originais e publicados na íntegra, disponíveis em língua portuguesa, espanhola e inglesa eletronicamente. Ademais, optou-se por estabelecer para a seleção dos artigos, estudos que fossem publicados no período de 2015 a 2019, por se tratar de um período que fornece informações mais atualizadas acerca do assunto. Por outro lado, como critérios de exclusão destacam-se os artigos que não respondiam à pergunta da pesquisa e os repetidos nas respectivas bases de dados mencionadas anteriormente.

Em virtude das características específicas para o acesso das bases de dados selecionadas LILACS, PUBMED e SCIELO, os métodos utilizados para localizar os artigos foram adaptados para cada uma. Após a leitura dos artigos encontrados em todas as bases de dados, apenas 11 publicações constaram como amostra final da pesquisa. Na base de dados LILACS, encontrou-se um total de 4 artigos. Na Biblioteca Eletrônica SCIELO, o cruzamento gerou nessa base um total de 2 artigos. E por fim, na base de dados PUBMED, obtevese 5 artigos.

Conforme semelhança entre os assuntos foram estabelecidas duas categorias temáticas de modo organizado e sistemático, sendo estas: 1) Abordagens de gênero na saúde do homem e 2) Abordagens de sexualidade, saúde sexual, reprodutiva e paternidade na saúde masculina. Para a coleta de dados dos artigos selecionados, foi realizada a leitura e o agrupamento dos artigos, escolhendo as partes mais importantes sobre a temática do estudo, que possibilitaram responder à questão norteadora. Após a seleção dos artigos que responderam aos critérios de inclusão, os mesmos foram impressos e catalogados em ordem numérica e organizados de acordo com o ano de publicação. Em seguida foi realizada a leitura minuciosa dos artigos, a fim de analisá-los com base nos objetivos estabelecidos.

Os estudos foram avaliados criteriosamente quanto à legitimidade, qualidade metodológica e importância da informação e foram apresentados em quadros com informações relevantes de cada artigo, possibilitando a análise e comparação dos mesmos com o conhecimento teórico, identificando lacunas pertinentes ao assunto e atendendo o escopo da pesquisa. Nessa fase também foram apresentados os resultados que consistiram em cruzar as informações retiradas dos artigos e mostrar os avanços no conhecimento bem como suas falhas. Ao fim da primeira análise da amostra pôde-se concluir que a análise dos artigos selecionados permitia responder à questão norteadora do estudo. Na discussão dos principais resultados dos artigos selecionados para a revisão integrativa, por meio de uma avaliação crítica, os estudos incluídos foram comparados, interpretados e debatidos no desenvolvimento da pesquisa.

\section{RESULTADOS}

A pesquisa na literatura resultou em onze artigos que se encaixam nos critérios de inclusão e demonstraram relevância para o estudo, evidenciando as abordagens de saúde sobre gênero e sexualidade no contexto de saúde do homem. O (Quadro 1) apresenta informações de título, autores, ano de publicação, revista, objetivos, métodos, a categoria na qual se encaixa o estudo e principais resultados/ considerações finais, dados estes retirados dos artigos selecionados. De forma fidedigna e respeitando todos os aspectos éticos e legais, as informações contidas no quadro remetem aos respectivos autores descritos. Foi realizado uma análise e seleção criteriosa dos estudos, que cominou num compêndio de conhecimentos valiosos sobre a saúde do homem, relevante aos profissionais de saúde com fim de melhorar a assistência de saúde prestada ao público masculino no contexto de gênero e sexualidade. 
Revista Eletrônica Acervo Saúde / Electronic Journal Collection Health ｜ ISSN 2178-2091

Quadro 1 - Caracterização dos artigos incluídos no estudo nas bases de dados LILACS, PUBMED e SCIELO 2019.

\begin{tabular}{|c|c|c|c|c|c|c|c|}
\hline & Titulo & Autor/Ano & Revista & Objetivo(s) & Método & Categoria & Resultados/Considerações finais \\
\hline 1 & $\begin{array}{lr}\text { Sentidos } & \text { da } \\
\text { Saúde } & \text { numa } \\
\text { Perspectiva } & \text { de } \\
\text { Gênero: } & \text { um } \\
\text { Estudo } & \text { com } \\
\text { Homens } & \text { da } \\
\text { Cidade } & \text { de } \\
\text { Natal/RN } & \end{array}$ & $\begin{array}{l}\text { Leite JF, et } \\
\text { al., } 2016 .\end{array}$ & $\begin{array}{l}\text { Psicologia: } \\
\text { Ciência e } \\
\text { Profissão. }\end{array}$ & $\begin{array}{l}\text { Investigar os sentidos } \\
\text { atribuídos à saúde por } \\
\text { homens da cidade de } \\
\text { Natal/RN. }\end{array}$ & $\begin{array}{l}\text { Estudo } \\
\text { descritivo, } \\
\text { qualitativo. }\end{array}$ & $\begin{array}{l}\text { Abordagen } \\
\text { s de gênero } \\
\text { na saúde } \\
\text { do homem }\end{array}$ & $\begin{array}{l}\text { Em posições sociais de gênero que conformam os } \\
\text { sentidos que homens construíram em relação à } \\
\text { saúde, atribuiu-se a esta a importância de } \\
\text { proporcionar o exercício de uma masculinidade } \\
\text { voltada para o provimento do lar e da família. } \\
\text { Atribuindo a UBS pouca resolutividade e } \\
\text { ineficácia do serviço. Sendo a busca de saúde no } \\
\text { nível de atenção básica limitada, assim estão } \\
\text { voltados à atenção especializada. }\end{array}$ \\
\hline 2 & $\begin{array}{l}\text { Encontros e } \\
\text { desencontros } \\
\text { entre a saúde do } \\
\text { homem, a } \\
\text { promoção da } \\
\text { paternidade } \\
\text { participativa e a } \\
\text { saúde sexual e } \\
\text { reprodutiva na } \\
\text { atenção básica }\end{array}$ & $\begin{array}{l}\text { Ribeiro CR, } \\
\text { et al., } 2017 .\end{array}$ & $\begin{array}{l}\text { Revista de } \\
\text { saúde } \\
\text { coletiva. }\end{array}$ & $\begin{array}{l}\text { Problematizar ações } \\
\text { desenvolvidas em UBS } \\
\text { voltadas para a saúde do } \\
\text { homem, paternidade } \\
\text { participativa e a saúde } \\
\text { sexual e reprodutiva. }\end{array}$ & $\begin{array}{l}\text { Estudo } \\
\text { descritivo, } \\
\text { com } \\
\text { abordagem } \\
\text { qualitativa. }\end{array}$ & $\begin{array}{l}\text { Sexualidad } \\
\text { e na saúde } \\
\text { do homem }\end{array}$ & $\begin{array}{l}\text { Para os homens as questões de gênero ainda são } \\
\text { impeditivas para essa inserção, assim como a } \\
\text { organização do próprio sistema; e que as ações } \\
\text { se organizam de forma fragmentada, atuando } \\
\text { sobre aspectos isolados da saúde masculina, não } \\
\text { contemplando o princípio da integralidade e } \\
\text { dificultando a promoção do vínculo desses } \\
\text { homens ao sistema pela atenção primária. }\end{array}$ \\
\hline 3 & $\begin{array}{l}\text { Sexualidade e } \\
\text { reprodução na } \\
\text { PNAISH: } \\
\text { reflexões a partir } \\
\text { da perspectiva de } \\
\text { gênero }\end{array}$ & $\begin{array}{l}\text { Dantas SMV, } \\
\text { Couto MT, } \\
2018 .\end{array}$ & $\begin{array}{l}\text { Revista } \\
\text { Latinoameri } \\
\text { cana. }\end{array}$ & $\begin{array}{l}\text { Mapear repertórios } \\
\text { relativos à sexualidade e } \\
\text { à reprodução presentes } \\
\text { na PNAISH }\end{array}$ & $\begin{array}{l}\text { Estudo } \\
\text { descritivo e } \\
\text { documental }\end{array}$ & $\begin{array}{l}\text { Sexualidad } \\
\text { e na saúde } \\
\text { do homem } \\
\text { masculina. }\end{array}$ & $\begin{array}{l}\text { Observou-se que a sexualidade é pouco } \\
\text { abordada, com ênfase na potência sexual. Não há } \\
\text { plena incorporação de discursos de } \\
\text { responsabilização igualitária pela reprodução e a } \\
\text { parentalidade. Ainda são necessárias ações que } \\
\text { trabalhem as resistências a maiores liberdades e } \\
\text { igualdades sexuais e reprodutivas. }\end{array}$ \\
\hline
\end{tabular}

REAS/EJCH | Vol.Sup.n.43 | e3000 | DOI: https://doi.org/10.25248/reas.e3000.2020 Página 4 de 10 


\section{Revista Eletrônica Acervo Saúde / Electronic Journal Collection Health ～ISSN 2178-2091}

\begin{tabular}{|c|c|c|c|c|c|c|c|}
\hline 4 & $\begin{array}{l}\text { Masculinidades } \\
\text { inerentes à } \\
\text { política brasileira } \\
\text { de saúde do } \\
\text { homem }\end{array}$ & $\begin{array}{l}\text { Cesaro BC, } \\
\text { et al., } 2018 .\end{array}$ & $\begin{array}{l}\text { Revista } \\
\text { Panam de } \\
\text { Salud } \\
\text { Publica. }\end{array}$ & $\begin{array}{lr}\text { Problematizar } & \text { a } \\
\text { incorporação } & \text { da } \\
\text { dimensão } & \text { das } \\
\text { masculinidades } & \text { como } \\
\text { fomentadora } & \text { de } \\
\text { estratégias de gestão na } \\
\text { PNAISH. }\end{array}$ & $\begin{array}{l}\text { Pesquisa } \\
\text { descritiva e } \\
\text { documental } \\
\text {. }\end{array}$ & $\begin{array}{l}\text { Abordagen } \\
\text { s de gênero } \\
\text { na saúde } \\
\text { do homem }\end{array}$ & $\begin{array}{l}\text { Nos discursos apontam que os homens buscam } \\
\text { os serviços de saúde apenas quando há } \\
\text { agravamento dos sintomas, desprovidos de uma } \\
\text { leitura que reconheça que os marcadores sociais } \\
\text { da diferença, produzem iniquidades em saúde. O } \\
\text { que influencia no seu reconhecimento como } \\
\text { sujeito de direito. Determinadas masculinidades } \\
\text { são invisíveis no interior de políticas públicas de } \\
\text { saúde e necessitam ser aprofundadas para } \\
\text { fomentar modos de pensar e fazer gestão em } \\
\text { saúde do homem. }\end{array}$ \\
\hline 5 & $\begin{array}{l}\text { Sou homem e pai } \\
\text { sim! } \\
(\text { Re)construindo } \\
\text { a identidade } \\
\text { masculina a partir } \\
\text { da participação } \\
\text { no parto }\end{array}$ & $\begin{array}{l}\text { Braide ASG, } \\
\text { et al., } 2018 .\end{array}$ & $\begin{array}{l}\text { Revista } \\
\text { Panam de } \\
\text { Salud } \\
\text { Publica. }\end{array}$ & $\begin{array}{l}\text { Compreender como as } \\
\text { experiências } \\
\text { participação ativa do } \\
\text { homem no pré-natal e no } \\
\text { parto influenciam a } \\
\text { ressignificação das } \\
\text { identidades masculinas. }\end{array}$ & $\begin{array}{l}\text { Estudo } \\
\text { qualitativo, } \\
\text { análise } \\
\text { antropológi } \\
\text { ca } \\
\text { interpretativ } \\
\text { a e suporte } \\
\text { etnográfico. }\end{array}$ & $\begin{array}{l}\text { Sexualidad } \\
\text { e na saúde } \\
\text { do homem } \\
\text { masculina. }\end{array}$ & $\begin{array}{l}\text { Observou-se a ressignificação das } \\
\text { masculinidades e promoção do autocuidado, na } \\
\text { compreensão de que a masculinidade não se } \\
\text { perde se houver uma participação do homem no } \\
\text { parto e cuidado dos filhos. A experiência de } \\
\text { participar do parto abriu uma possibilidade de } \\
\text { aproximação do homem aos sistemas de saúde } \\
\text { para a manutenção do bem-estar, ao invés de } \\
\text { necessariamente para o tratamento da doença. }\end{array}$ \\
\hline 6 & $\begin{array}{l}\text { Masculinity, } \\
\text { Social } \\
\text { Connectedness, } \\
\text { and Mental } \\
\text { Health: Men's } \\
\text { Diverse Patterns } \\
\text { of Practice }\end{array}$ & $\begin{array}{l}\text { Mckenzie } \\
\text { SK, et al., } \\
2018 .\end{array}$ & $\begin{array}{l}\text { American } \\
\text { Journal of } \\
\text { Men's } \\
\text { Health. }\end{array}$ & $\begin{array}{l}\text { Compreender como a } \\
\text { masculinidade e as } \\
\text { conexões sociais dos } \\
\text { homens pode afetar a } \\
\text { saúde mental destes. }\end{array}$ & $\begin{array}{l}\text { Estudo } \\
\text { qualitativo. }\end{array}$ & $\begin{array}{l}\text { Abordagen } \\
\text { s de gênero } \\
\text { na saúde } \\
\text { do homem }\end{array}$ & $\begin{array}{l}\text { No geral, os homens são menos capazes e } \\
\text { menos interessados do que as mulheres na } \\
\text { construção de emoções e relações de apoio com } \\
\text { os outros. As implicações dessas descobertas na } \\
\text { promoção da conexão social dos homens e saúde } \\
\text { mental devem ser discutidas. }\end{array}$ \\
\hline 7 & $\begin{array}{l}\text { Impacts of a } \\
\text { Documentary } \\
\text { about Masculinity } \\
\text { and Men's Health }\end{array}$ & $\begin{array}{l}\text { King K, et al., } \\
2018 .\end{array}$ & $\begin{array}{l}\text { American } \\
\text { Journal of } \\
\text { Men's } \\
\text { Health. }\end{array}$ & $\begin{array}{l}\text { Examinar a partir de um } \\
\text { documentário o impacto } \\
\text { deste sobre saúde do } \\
\text { homem. }\end{array}$ & $\begin{array}{l}\text { Pesquisa } \\
\text { qualitativa. }\end{array}$ & $\begin{array}{l}\text { Abordagen } \\
\text { s de gênero } \\
\text { na saúde } \\
\text { do homem. }\end{array}$ & $\begin{array}{l}\text { Os homens demonstraram mudanças } \\
\text { comportamentais associadas ao ajudar os outros } \\
\text { e serem mais expressivo emocionalmente. } \\
\text { Observa-se o potencial para que os resultados de } \\
\text { saúde dos homens sejam impactados } \\
\text { positivamente por novas intervenções de saúde } \\
\text { pública baseadas na mídia. }\end{array}$ \\
\hline
\end{tabular}

REAS/EJCH | Vol.Sup.n.43 | e3000 | DOI: https://doi.org/10.25248/reas.e3000.2020 Página $\mathbf{5}$ de $\mathbf{1 0}$ 


\section{Revista Eletrônica Acervo Saúde / Electronic Journal Collection Health ～ISSN 2178-2091}

\begin{tabular}{|c|c|c|c|c|c|c|c|}
\hline 8 & $\begin{array}{l}\text { Masculinity and } \\
\text { Depression: A } \\
\text { Longitudinal } \\
\text { Investigation of } \\
\text { Multidimensional } \\
\text { Masculine Norms } \\
\text { Among College } \\
\text { Men }\end{array}$ & $\begin{array}{l}\text { Iwamoto DK, } \\
\text { et al., } 2018 .\end{array}$ & $\begin{array}{l}\text { American } \\
\text { Journal of } \\
\text { Men's } \\
\text { Health. }\end{array}$ & $\begin{array}{l}\text { Examinar o papel de } \\
\text { normas masculinas } \\
\text { multidimensionais sobre } \\
\text { a sintomatologia } \\
\text { depressiva prospectiva } \\
\text { entre universitário. }\end{array}$ & $\begin{array}{l}\text { Estudo de } \\
\text { abordagem } \\
\text { qualitativa. }\end{array}$ & $\begin{array}{l}\text { Sexualidad } \\
\text { e na saúde } \\
\text { do homem } \\
\text { masculina. }\end{array}$ & $\begin{array}{l}\text { Normas masculinas distintas parecem conferem } \\
\text { risco de depressão enquanto outras normas } \\
\text { parecem ser protetoras. O que sugere que os } \\
\text { profissionais que trabalham com homens devem } \\
\text { avaliar a aderência de seus clientes a distintas } \\
\text { normas e explorar como elas podem impactar a } \\
\text { saúde mental. }\end{array}$ \\
\hline 9 & $\begin{array}{l}\text { "Think Like a } \\
\text { Man": How } \\
\text { Sexual Cultural } \\
\text { Scripting and } \\
\text { Masculinity } \\
\text { Influence } \\
\text { Changes in } \\
\text { Men's Use of } \\
\text { Intimate Partner } \\
\text { Violence }\end{array}$ & $\begin{array}{l}\text { Willie TCMA, } \\
\text { et al., } 2018 .\end{array}$ & $\begin{array}{l}\text { Am J J } \\
\text { Community } \\
\text { Psychol. }\end{array}$ & 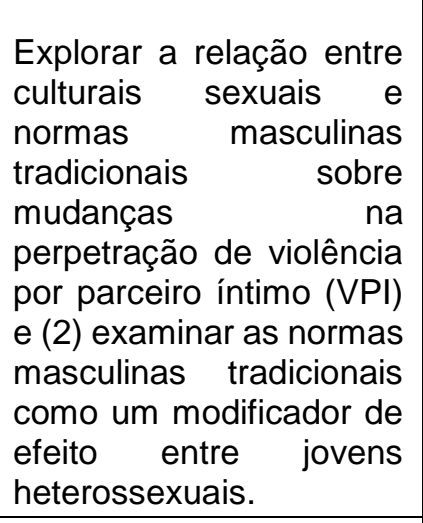 & $\begin{array}{l}\text { Estudo com } \\
\text { análise de } \\
\text { dados } \\
\text { secundária } \\
\text { de um } \\
\text { estudo de } \\
\text { coorte } \\
\text { prospectivo } \\
\text {. }\end{array}$ & $\begin{array}{l}\text { Abordagen } \\
\text { s de gênero } \\
\text { na saúde } \\
\text { do homem. }\end{array}$ & $\begin{array}{l}\text { Os resultados da regressão logística ajustada } \\
\text { revelaram que as normas de script cultural sexual } \\
\text { estavam associadas a um aumento nas chances } \\
\text { de perpetração emocional de VPI e as normas } \\
\text { masculinas tradicionais estavam associadas a um } \\
\text { aumento nas chances de penetração física de VPI } \\
\text { nos últimos seis meses. Não houve efeito de } \\
\text { interação significativo entre o script cultural sexual } \\
\text { e as normas masculinas tradicionais na } \\
\text { perpetração da VPI. Construções importantes } \\
\text { para entender a etiologia do uso da violência } \\
\text { pelos rapazes contra uma parceira. }\end{array}$ \\
\hline 10 & $\begin{array}{l}\text { Negotiating } \\
\text { Gender Norms to } \\
\text { Support Men in } \\
\text { Psychological } \\
\text { Distress }\end{array}$ & $\begin{array}{l}\text { Keohane A, } \\
\text { Richardson } \\
\text { N, } 2018 .\end{array}$ & $\begin{array}{l}\text { American } \\
\text { Journal of } \\
\text { Men's } \\
\text { Health. }\end{array}$ & $\begin{array}{l}\text { Investigar como as } \\
\text { normas masculinas } \\
\text { afetam os homens na } \\
\text { procura por ajuda } \\
\text { psicológica. }\end{array}$ & $\begin{array}{l}\text { Estudo } \\
\text { qualitativo } \\
\text { com grupos } \\
\text { focais. }\end{array}$ & $\begin{array}{l}\text { Abordagen } \\
\text { s de gênero } \\
\text { na saúde } \\
\text { do homem. }\end{array}$ & $\begin{array}{l}\text { A busca de ajuda dos homens é uma construção } \\
\text { passiva e unidimensional, para uma tríade mais } \\
\text { dinâmica de comportamentos de busca de ajuda, } \\
\text { doação e aceitação incorporadas no contexto } \\
\text { sociocultural da vida dos homens. }\end{array}$ \\
\hline 11 & $\begin{array}{lr}\text { PNAISH: } & \text { uma } \\
\text { análise de } & \text { sua } \\
\text { dimensão } & \\
\text { educativa } & \text { na } \\
\text { perspectiva } & \text { de } \\
\text { gênero } & \end{array}$ & $\begin{array}{l}\text { Pereira J, et } \\
\text { al., } 2019 .\end{array}$ & $\begin{array}{l}\text { Saúde } \\
\text { Sociedade } \\
\text { São Paulo. }\end{array}$ & $\begin{array}{l}\text { Discutir alguns dos } \\
\text { modos pelos quais o } \\
\text { gênero atravessa as } \\
\text { proposições da Política } \\
\text { Nacional de Atenção } \\
\text { Integral da Saúde do } \\
\text { Homem (PNAISH). }\end{array}$ & $\begin{array}{l}\text { Estudo } \\
\text { descritivo e } \\
\text { documental }\end{array}$ & $\begin{array}{l}\text { Abordagen } \\
\text { s de gênero } \\
\text { na saúde } \\
\text { do homem. }\end{array}$ & $\begin{array}{l}\text { Dentro do contexto discursivo de integralidade e } \\
\text { equidade apesentados e acionados nas } \\
\text { propostas de saúde e ações educativas de } \\
\text { homens na PNAISH, ao mesmo tempo em que } \\
\text { essa amplitude coloca sob suspeita determinadas } \\
\text { formas de viver a masculinidade, ela não desloca } \\
\text { a centralidade dos processos curativos e parece } \\
\text { contribuir para impregnar a política com uma } \\
\text { visão utilitária, individualizando e culpabilizando } \\
\text { os homens por seu distanciamento dos serviços } \\
\text { de saúde. }\end{array}$ \\
\hline
\end{tabular}

Fonte: Queiroz IBS, et al., 2020.

REAS/EJCH | Vol.Sup.n.43 | e3000 | DOI: https://doi.org/10.25248/reas.e3000.2020 Página 6 de 10 
No tocante ao período de publicação entre os estudos selecionados, as pesquisas apresentavam predomínio no ano de 2018 , sendo $8(72,7 \%)$ do total de artigos. Referente à revista, destaca-se a American Journal of Men's Health que se configurou como a de maior prevalência, apresentando $4(36,3 \%)$ de obras na amostra.

Os objetivos propostos pelos estudos analisados, em sua maioria, tinham como finalidade identificar os impactos da masculinidade e construções de gênero nos mais diversos comportamentos de saúde dos homens, assim como na participação destes na saúde sexual e reprodutiva. Dentre os métodos de estudo mais utilizados, destaca-se entre eles, 7 (63,6\%) artigos com métodos de estudo descritivo de abordagem qualitativa.

Em relação aos tipos de estratégias ou técnicas implementadas para abordagem de saúde do homem, foi possível observar a existência de duas mais expressivas: Abordagens de gênero na saúde do homem e Abordagens de sexualidade, saúde sexual, reprodutiva e paternidade na saúde masculina. Ambas influenciadas pelo contexto sociocultural de estereótipo de identidade masculina com a necessidade da ressignificação do ser homem no contexto de saúde no Brasil. A estratégia por meio da superação da visão de gênero foi predominante nos artigos.

\section{DISCUSSÃO}

Na leitura, interpretação e comparação dos artigos, destacaram-se as abordagens de gênero que de forma estereotipada acabam por interferir no atual contexto de saúde do homem e abordagens de sexualidade, que influenciam sobremaneira na própria saúde masculina, bem como na saúde do núcleo familiar.

Logo, para melhorar a discussão dos resultados dos artigos, optou-se por categorizar em: 1) Abordagens de gênero na saúde do homem; e 2) Abordagens de sexualidade, saúde sexual, reprodutiva e paternidade na saúde masculina.

Categoria 1: Abordagens de gênero na saúde do homem.

Socialmente o exercício da masculinidade está ligado às questões de provimento financeiro do lar e da família, em especial faz-se necessário entender de que forma esses estigmas culturais de gênero impactam a saúde da população masculina. Quando comparado a outros grupos, identifica-se que os homens apresentam um nível limitado de busca pelos serviços básicos e preventivos de saúde, e que estes buscam quando demandam de atenção especializada. A procura se dar por serviços emergenciais e de farmácia para que sem perda de tempo os problemas de saúde possam ser solucionados. Tal contexto demonstra como as questões de gênero influenciam na saúde. Os homens atribuem à saúde um sentido de primordialidade, mas as experiências de atendimentos anteriores, pautadas na satisfação e resolubilidade, os levam a qualificar a saúde de forma positiva ou negativa (LEITE JF, et al., 2016). As ciências médicas ainda não enxergam os homens como seres construídos historicamente pelas relações de gênero e sim como generalizados, desprezando assim suas singularidades e individualidades.

Com vista a aprofundar essa discussão, Cesaro BC, et al. (2018) problematizaram a incorporação da dimensão das masculinidades como fomentadora de estratégias de gestão na PNAISH, e identificaram que os discursos reducionistas sobre o estigma do ser homem e sua relação com saúde são desprovidos de uma reflexão que outros indicadores, como classe social e raça, produzem iniquidades em saúde, influenciando no reconhecimento como sujeito de direitos, desigualdade, discriminação, vulnerabilidades e adoecimento dos homens. Percebe-se que existem diversas masculinidades, nas quais algumas são inferiorizadas em detrimento de outras, como o que ocorre com a reafirmação da sexualidade para homens negros, gays e de baixa renda. Necessitando de uma abordagem interseccional entre diferentes políticas e pontos de atenção nas redes de saúde que dê visibilidade as pluralidades na saúde do homem.

A perspectiva de gênero perpassa as proposições da PNAISH, com vista à integralidade e equidade são discutidas propostas de educação e cuidado voltadas a saúde do homem, ainda impregnada com estigmas da masculinidade e centralizada em processos curativos, o que por vezes culpabiliza o homem por seu distanciamento dos serviços de saúde. Embora a prática revele que diversos são os entraves, como barreiras institucionais, questões culturais e frágeis modelos de atenção (PEREIRA J, et al., 2019). 
Ainda sobre como a construção social de gênero impacta a saúde dos homens, destaca as abordagens de saúde mental ao público masculino, uma vez que a literatura demonstra que as conexões sociais e as redes de apoio influenciam na saúde mental. Contudo, poucos são os estudos que avaliam como os homens mobilizam essa rede de apoio.

Com isso, Mckenzie SK, et al. (2018) relacionaram a masculinidade à saúde mental e demonstraram que os homens apresentam conexões sociais diversas, ora buscam e mobilizam apoio social, e ora evidenciam rejeição a esse apoio. Os estereótipos de gênero levam a abordagens que veem os homens como menos capazes e menos interessados no crescimento e desenvolvimento de emoções, sendo uma barreira para aqueles que optam por buscar ativamente apoio emocional de suas redes, o que poderia isolá-los socialmente, reduzindo as oportunidades de apoio social durante eventos difíceis da vida, romper relacionamentos e conexões, prejudicando a saúde e bem-estar mental desses homens. Faz-se necessário uma atenção individualizada e singular a essa população pluralizada.

Ainda no campo da saúde mental masculina, destaca-se a necessidade de estratégias de prevenção do suicídio, que abordem as causas da desconexão dos homens das principais instituições sociais como família, educação e comunidade, principalmente nas populações mais marginalizadas. A masculinidade afeta não só os homens quanto à busca de apoio psicológico, mas também os profissionais de saúde, que precisam identificar circunstâncias oportunas em que os homens se mostram disponíveis e abertos à ajuda emocional, estando atentos ao contexto de vida singular de tais pacientes (KEOHANE A e RICHARDSON N, 2018).

Acompanhando a atual globalização da saúde, King K, et al. (2018) utilizaram-se de mídias digitais e desenvolveram um documentário que explorava a relação entre masculinidade, saúde mental e suicídio. A análise do feedback qualitativo masculino demonstrou positividade no impacto da utilização da ferramente de educação na transformação de atitudes e comportamentos, como mudança de opinião sobre o significado de ser homem; maior conscientização sobre saúde mental e suicídio; a importância de expressar sentimentos; e a importância de procurar ajuda; além de uma maior preocupação para com o outro. Os homens demonstraram aceitar melhor a normalidade de que eles também experimentam problemais emociais, andando em sentido contrário às pressões sociais. Ressalta-se a importância das intervenções de saúde pública baseadas na mídia na saúde masculina.

A segurança pública constitui outro setor afetado pelas implicações negativas dos estereótipos de masculinidade. Dessa forma, tem-se desenvolvido estudos com inovações acadêmicas de pesquisa que exploram a relação entre fatores culturais sociais e violência de parceiro íntimo (VPI). Frente a essa realidade, um estudo analisou tais influências da masculinidade através de um conceito novo, o script cultural sexual. $E$ revelou que as normas de script cultural sexual se associam a um aumento da perpetração emocional de VPI e as normas masculinas tradicionais associam-se a um aumento na penetração física de VPI nos últimos seis meses. Essas normas de masculinidade são institutos importantes a serem considerados nas abordagens de saúde que envolvem o contexto de violência praticada por homens contra suas parceiras. Enquanto as principais intervenções de VPI abordam a masculinidade, o script cultural sexual revelou-se como um conceito adicional que também deve ser abordado (WILLIE TCMA, et al., 2018).

Categoria 2: Abordagens de sexualidade, saúde sexual, reprodutiva e paternidade na saúde masculina.

Os direitos sexuais e reprodutivos são inerentes à condição humana, e assim equalizam homens e mulheres. Porém, as políticas públicas encontram barreiras sociais para sua implementação. Apenas mulheres engravidam e com isso, a maioria dos métodos contraceptivos é direcionada ao controle feminino em primeira instância. Para além dessa questão de sexo, existem outros fatores, como marcadores socioeconômicos, de raça, etnia, idade, orientação sexual, entre outros. Assim o foco das ações e serviços de saúde sexual é a mulher, sendo esta responsável pelo planejamento reprodutivo. Como se observa que a cirurgia de esterilização masculina é pouco praticada e conhecida em relação à feminina. Mesmo referente à vasectomia, a presença masculina se dá não para o planejamento, mas para a realização do procedimento cirúrgico. Ainda sobre sexualidade a vasectomia é permeada pelo medo da disfunção erétil, as consultas preparatórias para a cirurgia não são ambientes de discussão sobre sexualidade e sim de meras explicações sobre a relação da cirurgia com a preservação da função erétil e penetrativa. Logo, desperdiça-se um espaço propício para debates sobre saúde do homem com foco preventivo (RIBEIRO CR, et al., 2017). 
Assim não há oportunidade plena para a inserção do homem nesses serviços e a integralidade encontrase comprometida uma vez que o homem é reduzido ao estereótipo de ser forte, viril e indisciplinado nos cuidados com a saúde. Em confronto com a ideia de que é puramente feminina a demanda que se refere à saúde sexual, reprodutiva e paternidade, a PNAISH propõem melhorias e condições ao exercício masculino dessas funções.

Entretanto, Dantas SMV e Couto MT (2018) realizaram um estudo que mapeou os repertórios relativos à sexualidade e à reprodução presente na $\mathrm{PNAISH}$, e identificaram que a sexualidade em sentido amplo é pouco abordada, tendo maior destaque as especialidades, ato e potência sexual, medicalização, pouco evidenciando o caráter relacional das questões de sexualidade. Embora haja um empenho em promover o envolvimento masculino de forma prazerosa e participativa no pré-natal, parto, cuidado com os filhos e saúde sexual e reprodutiva. Essas preocupações do Ministério da Saúde por muitas vezes não são acompanhadas na mesma intensidade em âmbito municipal, sendo os homens ainda coadjuvantes nesse cenário. Cabe ainda destacar que as abordagens de saúde reprodutiva e paternidade na PNAISH estão voltadas para as famílias heterossexuais e consanguíneas, reforçando os estereótipos.

Necessita-se da cooperação de atores sociais, institucionais e políticos para mudanças dos paradigmas culturais e das relações de poder, de forma que se possibilite a real incorporação dos homens nas ações de saúde. Tal incorporação pode ser percebida, a exemplo de abordagens de saúde com o foco na figura do homem que permitiram a experiência da participação ativa destes no pré-natal e parto, vindo a influenciar na ressignificação das identidades masculinas, na percepção de paternidade e na promoção do autocuidado, superando entraves impostos pela sociedade patriarcal. Superação está também possibilitada pela maior inserção feminina no mercado de trabalho e progressiva redução do papel paterno de provedor. A masculinidade não se perde quando o homem desempenha papel ativo no parto e cuidado com os filhos, pelo contrário estabeleceu-se um ambiente para o desenvolvimento da promoção de saúde masculina (BRAIDE ASG, et al., 2018).

As pressões sociais impõem aos homens uma constante necessidade de prova de sua masculinidade sexual, fato esse que gera impacto sobre o bem-estar e saúde mental dos mesmos. De acordo com Iwamoto DK, et al. (2018), em um estudo realizado nos Estados Unidos que analisaram a influência das normas de masculinidade na saúde mental de homens universitários, e constataram que as normas masculinas estavam positiva e negativamente relacionadas ao risco para depressão, de modo que os homens que aderiam normas masculinas de autossuficiência desejo de ter múltiplos parceiros sexuais e violência aumentavam o grau de risco, enquanto os homens que não se utilizavam dessas afirmações masculinas eram menos propensos a relatar sintomatologia depressiva. Associam-se normas masculinas distintas ao risco de depressão, enquanto outras normas são estabelecidas como protetoras.

\section{CONSIDERAÇÕES FINAIS}

As questões de gênero somadas à organização do próprio sistema, com ações estanques e fragmentadas, tem dificultado a promoção do vínculo dos homens ao sistema pela atenção primária. O cotidiano dos serviços de saúde revela que há diferenças nas abordagens para homens e mulheres em relação ao pré-natal, parto, cuidado dos filhos, saúde sexual e reprodutiva, marcadas pelos estigmas de masculinidade. Desse modo, tal diferenciação contribui para a manutenção do paradigma de saúde do homem, invisibilizando e isolando estes dessas ações de cuidado. E assim, faz-se necessário que os meios acadêmico e profissional se esforcem pela mudança do atual cenário de saúde masculina, a fim de desenvolver uma saúde do homem de maneira integral e equânime.

\section{REFERÊNCIAS}

1. CARNEIRO LMR, et al. Atenção integral à saúde do homem: um desafio na atenção básica. Ver Bras Promoç Saúde, Fortaleza. 2016; 29(4): 554-563.

2. CARRARA $S$, et al. A política de atenção à saúde do homem no Brasil: os paradoxos da medicalização do corpo masculino. Physis. 2009; 19(3): 659-678. 
3. MINISTÉRIO DA SAÚDE (BR), Secretaria de Atenção à Saúde, Departamento de Ações Programáticas Estratégicas. Política nacional de atenção integral à saúde do homem: princípios e diretrizes. Brasília: Ministério da Saúde. 2009.

4. CONNEL RW, MESSERSCHMIDT JW. Masculinidade hegemônica: repensando o conceito. Estud Fem. 2013; 21(1): 241-282.

5. BATISTA KSA, LIMA AF. Por uma implicação política e conceitual nos estudos sobre homens, masculinidades e violência de gênero. Semina Cienc Soc Hum. 2017; 38(2): 175-188.

6. MEYER, D. et al. Vulnerabilidade, gênero e políticas sociais: a feminização da inclusão social. Revista Estudos Feministas, Florianópolis. 2014; 22(3): 885-904.

7. MENDES KDS, et al. Revisão integrativa: método de pesquisa para a incorporação de evidências na saúde e na enfermagem. Texto contexto - enferm. 2008; 17(4): 758-764.

8. LEITE JF, et al. Sentidos da Saúde numa Perspectiva de Gênero: um Estudo com Homens da Cidade de Natal/RN. Psicologia: Ciência e Profissão. 2016; 36(2): 341-353.

9. CESARO BC, et al. Masculinidades inerentes à política brasileira de saúde do homem. Rev Panam de Salud Publica. 2018; 42: 119-125.

10. PEREIRA J, et al. PNAISH: uma análise de sua dimensão educativa na perspectiva de gênero. Saúde Soc. São Paulo. 2019; 28(2): 132-146.

11. MCKENZIE SK, et al. Masculinity, Social Connectedness, and Mental Health: Men's Diverse Patterns of Practice. American Journal of Men's Health. 2018; 12(5): 1247-1261.

12. KEOHANE A, RICHARDSON N. Negotiating Gender Norms to Support Men in Psychological Distress. American Journal of Men's Health. 2018; 12(1): 160-171.

13. KING K, et al. Impacts of a Documentary about Masculinity and Men's Health.American Journal of Men's Health. 2018; 12(5): 1604-1614.

14. WILLIE TCMA, et al. "Think Like a Man": How Sexual Cultural Scripting and Masculinity Influence Changes in Men's Use of Intimate Partner Violence. Am J Community Psychol. 2018; 61(2): 240-250.

15. RIBEIRO CR, et al. Encontros e desencontros entre a saúde do homem, a promoção da paternidade participativa e a saúde sexual e reprodutiva na atenção básica. Physis Revista de Saúde Coletiva. 2017; 27 (1): 41-60.

16. DANTAS SMV, COUTO MT. Sexualidade e reprodução na Política Nacional de Saúde do Homem: reflexões a partir da perspectiva de gênero. Revista Latinoamericana. 2018; (30): 99-118.

17. BRAIDE ASG, et al. Sou homem e pai sim! (Re)construindo a identidade masculina a partir da participação no parto. Rev Panam Salud Publica. 2018; 42: 190-194.

18. IWAMOTO DK, et al. Masculinity and Depression: A Longitudinal Investigation of Multidimensional Masculine Norms Among College MenAmerican Journal of Men's Health. 2018; 12(6): 1873-1881. 